\title{
Research on Switching Model of Microgrid with Distributed Power Supply
}

\author{
LIU Meiyin ${ }^{1}$, LV Zhenhua ${ }^{2}$, WU Beibei ${ }^{1}$, GUO Chongyang ${ }^{1}$, and HAN Pingping ${ }^{3}$ \\ ${ }^{1}$ Renewable Energy Research Center, State Key Laboratory of Operation and Control of Renewable Energy \& Storage Systems, China \\ Electric Power Research Institute, Beijing, China \\ ${ }^{2}$ Power Grid Technology Center, Power Science Research Institute of State Grid Jiangsu electric power CO,. LTD, Nanjing, China \\ ${ }^{3}$ HeFei University of Technology, Hefei, China
}

\begin{abstract}
The hybrid microgrid with distributed power supply which includes wind turbine (WT), photovoltaic (PV) inverter and power converter system (PCS), not only could be connected to the power distribution network, but also can operate independently. It is realized switch from grid-connected mode to off-grid mode through the microgrid controller. Whether the microgrid can achieve smooth switching from grid-connected to off-grid has great influence on the safety and stability of the power grid. In order to accurately evaluate the influence of the microgrid switch to the distribution network, it is needed to research on the distributed source modeling technology, and establish an accurate microgrid model. In this paper, using a 400V voltage grade microgrid system with PV, WT and PCS as an example, model the internal equipment and the microgrid control system, and establish a microgrid model for simulation. At the meantime, it carries out the microgrid switch testing, and compare with the measured waveform to verify the accuracy of the model. It is confirmed the accuracy of the microgrid model by the contrast result.
\end{abstract}

\section{Introduction}

The renewable energy resources are abundant, such as wind power and solar power, but because of their inherent characteristics such as volatility and randomness, in order to improve the system stability, the corresponding energy storage system should be configured to suppress the power fluctuation in practical application [1-3]. The renewable energy resources are used as distributed power supply which are connected to the distribution network in the role of microgrid, and supported each other with the distribution network. It is an effective way to play the functions of the distributed generation system [4]. The integrated utilization of wind power, PV and energy storage is an autonomous system that can realize control, protection and management by itself. It can operate in parallel with the large power grid, and it can also run in isolation [5]. The switching function which switches from grid-connected to off-gird is one of the basic functions of microgrid. In order to obtain accurate microgrid switching model, it is necessary to study the accurate key equipment and control system model of microgrid. Distributed generation and microgrid modeling technology have been widely studied. The calibration method of PV inverter model is proposed in literature [6], but only the accuracy of grid-connected PV inverter model is explained. Literature [7] presents an algorithm for optimal sizing of the WT, PV and the battery energy storage system in the grid-connected configuration of a microgrid, but there is no mention of modeling methods. Literature [8] describes two PV modeling methods and their performance, but it's no analysis of other distributed power access to the microgrid. Literature [9] describes and evaluates the feasibility of control strategies to be adopted for the operation of a microgrid when it becomes isolated. It presents an evaluation of the need of storage devices and load shedding strategies, but it does not analyze the switching capability of microgrid. At home and abroad, researches on microgrid including wind power, PV and PCS have been carried out. However, there is a lack of comparative research on switching strategy simulation and field testing.

Based on this, this paper makes a complete modeling and experimental analysis of the microgrid system composed of WT, PV and PCS. It studies on the dynamic behavior of the microgrid under the grid-connected conditions and the island conditions, and the switching situation between grid-connected and island condition. Taking the microgrid system of the academy of electrical engineering as an example, the internal equipment and control system of the microgrid are modeled and analyzed. The system includes $30 \mathrm{~kW}$ horizontal axis WT, $5 \mathrm{~kW}$ rotor WT, $5 \mathrm{~kW} \mathrm{H}$ airfoil WT, $30 \mathrm{~kW}$ fixed polycrystalline PV power inverter, $75 \mathrm{kWh}$ lithium battery energy storage, simulated load and so on.

\section{Control strategy}




\subsection{Microgrid control mode}

At present, there are two kinds of control strategies for microgrid: master-slave control and peer to peer ${ }^{[10]}$. In this paper, the master-slave control method is adopted in the microgrid system. When the microgrid is girdconnected, the battery and other distributed power are controlled by constant power (P/Q control). When the microgrid is in an isolated island operation mode, the bidirectional PCS adopts constant voltage and constant frequency control (U/f control).

The control mode of the microgrid is mainly realized by the switching mode of bidirectional PCS. When the microgrid is connected to gird, the PCS uses PQ control mode to output active power. When the microgrid is under isolated network operation, the PCS maintains the voltage and frequency of the microgrid, and tracks the output power and load fluctuation of the WTs and the PVs.

\subsection{Control strategy of PV inverter}

The PV inverter uses SPWM modulated voltage and current closed loop control to realize the inverter power decoupling control. Based on the equivalent power transformation, the three-phase stationary coordinate system $A B C$ is converted to the two-phase rotating coordinate $\mathrm{d} / \mathrm{q}$ system. The external loop voltage, reactive power control and inner loop current control system are established in the $\mathrm{d} / \mathrm{q}$ coordinate system. The control strategy model is shown in Figure 1. $\mathrm{U}_{\mathrm{dc}}$ and Q are the measured values of direct voltage and reactive power respectively. $U_{\text {dcref }}$ and $Q_{\text {ref }}$ are the given reference values of direct voltage and reactive power respectively. $i_{d}$ and $i_{q}$ are the measured values of $d / q$ axis component of the AC side current respectively. $i_{\text {dref }}$ and $i_{\text {qref }}$ are the given reference values of d/q axis component of the AC side current respectively. ia ib、ic and ua ub、uc are the three-phase instantaneous current and voltage data. $\mathrm{P}_{\mathrm{mr}}$ and $\mathrm{P}_{\mathrm{mi}}$ are the drive sign of inverter.

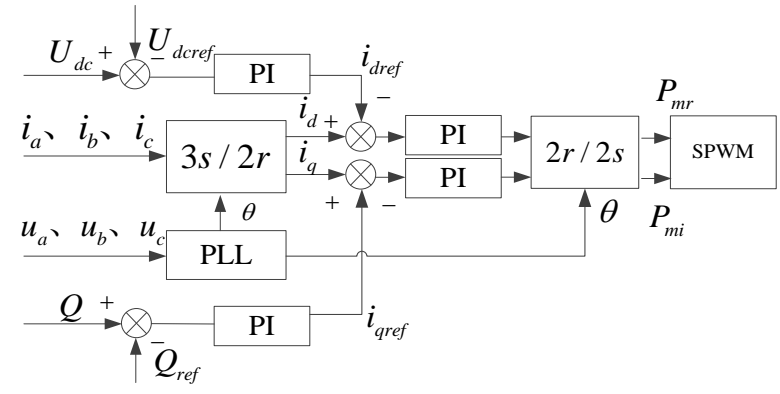

Fig. 1. Schematic diagram of control strategy for PV Inverter.

\subsection{Control strategy of direct-driven wind turbine generators}

As shown in the Figure 2, the topology diagram of the direct-drive synchronous wind power generation system, the model structure of the direct-drive wind turbine can be divided into several main parts: mechanical control model, direct-drive synchronous motor, generator-side converter model, grid-side converter model and DC link.

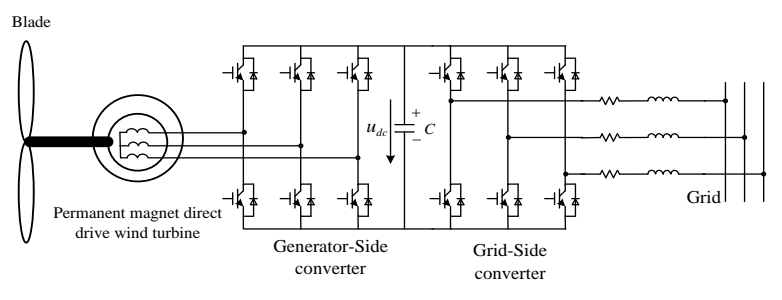

Fig. 2. Topological structure diagram of direct-drive synchronous wind power generation system.

The mechanical control model includes the aerodynamic model of the wind turbine, the control of the pitch angle and the model of the actuator, the shaft model and the MPPT model. The output of the mechanical torque and the maximum power reference value are used as the input of the next module.

The three-phase voltage type PWM converter on the generator side can rectify the alternating current to direct current in amplitude and frequency, and by adjusting the $\mathrm{d}$ axis and the $\mathrm{q}$ axis components of the stator current of the generator side, the decoupling control of the electromagnetic torque and the stator reactive power (usually set as 0) can be realized, so as to realize the unit power factor of the generator. The factor output also realizes the adjustment of the speed of the wind turbine when the wind speed changes. It can not only make the generator run in the variable speed constant frequency state, but also realize the maximum wind energy capture function under the rated wind speed. The converter on the generator side uses the vector control of the rotor flux orientation of the generator. The control model of the generator-side converter is shown in Figure 3. $\mathrm{P}_{\mathrm{e}}$ and $\mathrm{P}_{\text {eref }}$ are active power measured values and reference values in the generator side. $\mathrm{Q}_{\mathrm{e}}$ and $\mathrm{Q}_{\text {eref }}$ are reactive power measured values and reference values in the generator side. $i_{\text {sd }}$ and $i_{\text {sdref }}$ are the d-axis current measured values and reference values in the generator side. $i_{s q}$ and $i_{s q r e f}$ are the $\mathrm{q}$-axis current measured values and reference values in the generator side. $\omega_{\mathrm{r}} \mathrm{L}_{\mathrm{d}} \mathrm{i}_{s d} / \omega_{\mathrm{r}} \mathrm{L}_{\mathrm{q}} \mathrm{i}_{\mathrm{sq}}$ are $\mathrm{d} / \mathrm{q}$ axis impedance voltage. $\mathrm{U}_{\mathrm{sd}} / \mathrm{U}_{\mathrm{sq}}$ are $\mathrm{d} / \mathrm{q}$ axis voltage values in the generator side.

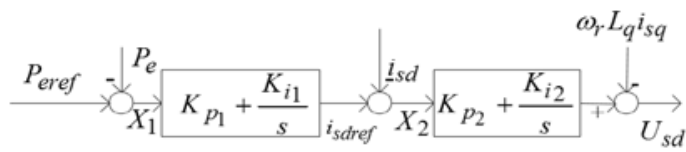

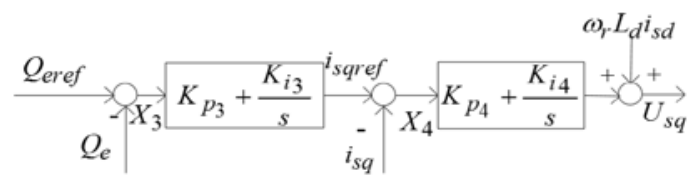

Fig. 3. Generator-side converter and its control model.

The three-phase voltage type PWM converter is used in the grid-side converter, and the three-phase voltage type PWM converter of the grid side controls the reactive current through the PI controller to control the reactive power exchange of the converter and the power grid and 
regulates the active current to control the constant voltage of the DC bus and the output power of the generator side. Grid side converter adopts grid voltage oriented vector control strategy to realize decoupling control. The control model of the generator-side converter is shown in Figure $4 . U_{\mathrm{dc}}$ and $U_{\mathrm{dcref}}$ are direct voltage measured values and reference values in the grid side. $\mathrm{Q}_{\mathrm{g}}$ and $\mathrm{Q}_{\text {gref }}$ are reactive power measured values and reference values in the grid side. $i_{\text {gd }}$ and $i_{\text {gdref }}$ are the $d$ axis current measured values and reference values in the grid side. $i_{\text {gq }}$ and $i_{\text {gqref }}$ are the q-axis current measured values and reference values in the grid side. $\omega_{\mathrm{r}} \mathrm{L}_{\mathrm{g}} \mathrm{i}_{\mathrm{gd}} / \omega_{\mathrm{r}} \mathrm{L}_{\mathrm{g}} \mathrm{i}_{\mathrm{gq}}$ are $\mathrm{d} / \mathrm{q}$-axis impedance voltage. $\mathrm{U}_{\mathrm{gd}} / \mathrm{U}_{\mathrm{gq}}$ are $d / q$ axis voltage values in the grid side.

$$
\underset{Q_{g}}{\stackrel{Q_{g r e f}}{U_{X_{7}}}}
$$

Fig. 4. Grid-side converter and its control model.

\subsection{Control strategy of bidirectional PCS}

Voltage converter is usually used in bidirectional PCS. An important role of PCS in microgrid is to stabilize power fluctuation in microgrid and realize dynamic balance of power in microgrid. Therefore, when PCS is connected to the grid, PQ control is usually adopted. The control target of PQ control is that the active and reactive power of PCS can follow the instruction value. The PQ control essentially controls the PCS as a controlled current source, and between the PCS and the microgrid is actually equivalent to a parallel connection between an AC power source and a voltage source, while the PCS output voltage is automatically clamped to the grid voltage when the grid is connected.

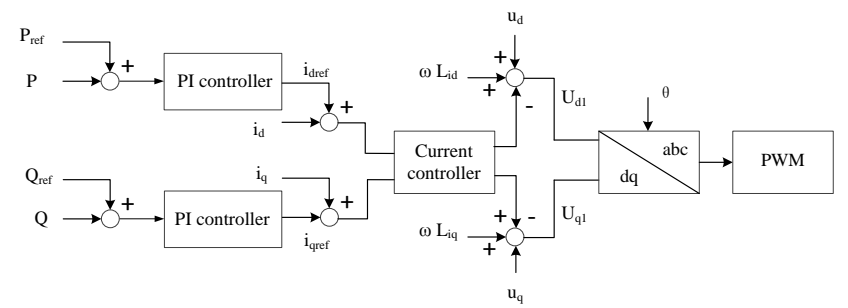

Fig. 5. P/Q control block diagram of PCS.

In the Figure 5, $\mathrm{P}_{\text {ref }}$ and $\mathrm{Q}_{\text {ref }}$ are respectively the power given reference values; $\mathrm{P}$ and $\mathrm{Q}$ are the measured values of the power respectively; $\mathrm{id}_{\mathrm{ref}}$ and $\mathrm{iq}_{\mathrm{ref}}$ are the given reference values of the $d / q$ axis components of the AC side current respectively; $i_{d}$ and $i_{q}$ are the actual values of the $d / q$ axis component of the AC side current respectively. $u_{d}$ and $u_{q}$ are the actual values of the output voltage of the inverter respectively. The reference value of output voltage $\mathrm{d} / \mathrm{q}$ axis component; $\mathrm{L}$ is AC side coupling inductance; $\theta$ is voltage initial phase angle.

The AC voltage output of the PCS can be equivalent to a controllable voltage source, and its frequency, phase and amplitude must be coordinated to share the load current. Droop control is used to solve the current sharing problem of multiple PCSs in parallel. And when multiple PCSs run in parallel, each converter can respond to the load changes in a predetermined way. It does not need to obtain data from other converters from the system. Based on local information operation, each converter has the ability to plug and play.

\section{Modeling and simulation analysis of microgrid}

Based on the above distributed power model structure, building the model in the power system simulation software. The block diagram of PV inverter in DIgSILENT software is shown in Figure 6.

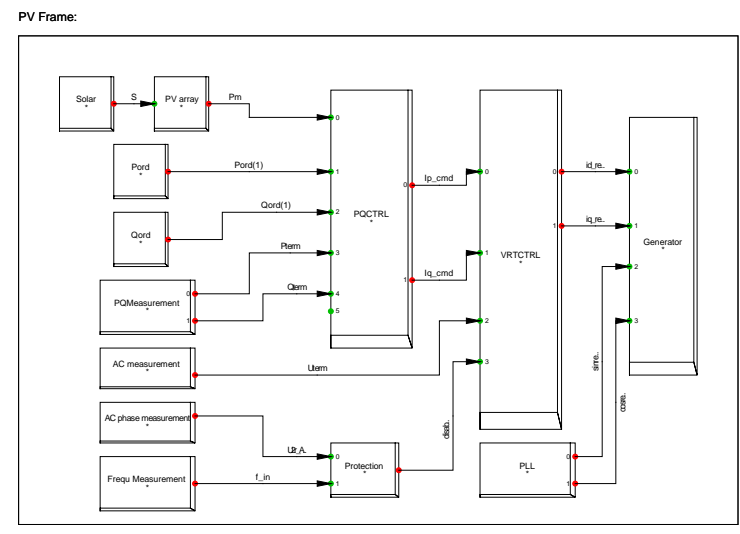

Fig. 6. PV inverter grid-connected control block diagram.

The block diagram of WT in DIgSILENT software is shown in Figure 7.

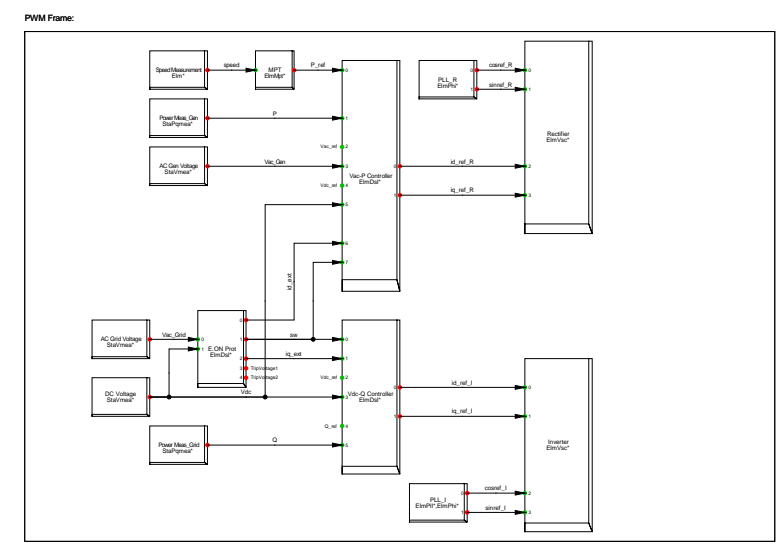

Fig. 7. Direct-driven WT grid-connected control block diagram.

The block diagram of PCS in DIgSILENT software is shown in Figure 8. 


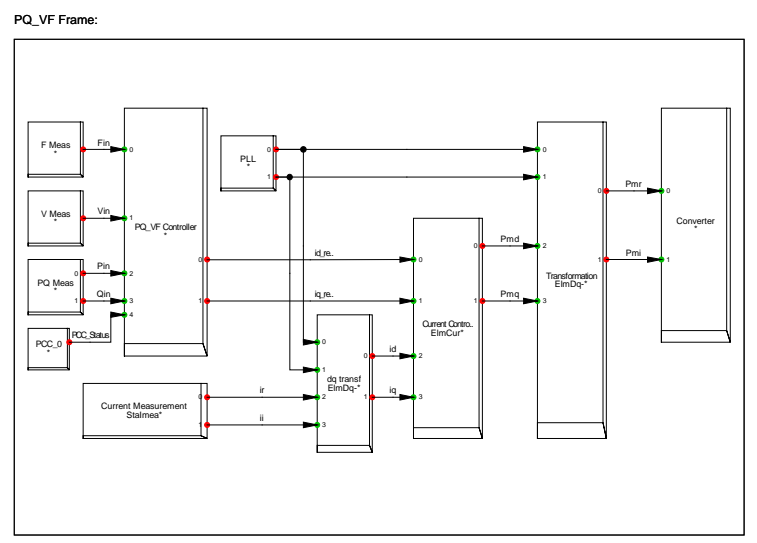

Fig. 8. PCS grid-connected control block diagram.

Take a microgrid as an example, the microgrid includes 30kW horizontal axis WT, 5kW rotor WT, 5kW $\mathrm{H}$ airfoil $\mathrm{WT}, 30 \mathrm{~kW}$ fixed polycrystalline $\mathrm{PV}$ power inverter, 75kWh lithium battery energy storage, wind turbine, PV power inverter, energy storage converter are connected to $0.4 \mathrm{kV}$ bus in parallel, after one booster transformer to access $10 \mathrm{kV}$ bus, and achieve gridconnected power generate. Based on the DIgSILENT software platform, a model which includes WT, PV inverter and PCS is set up, and the basic network control block diagram is shown in Figure 9. Based on the above model of PV inverter, WT, PCS, and transformer, line and load model are used to simulate the whole microgrid. The power grid model adopts the ideal voltage source, the voltage and frequency of which can be adjusted. It is shown in figure 9.

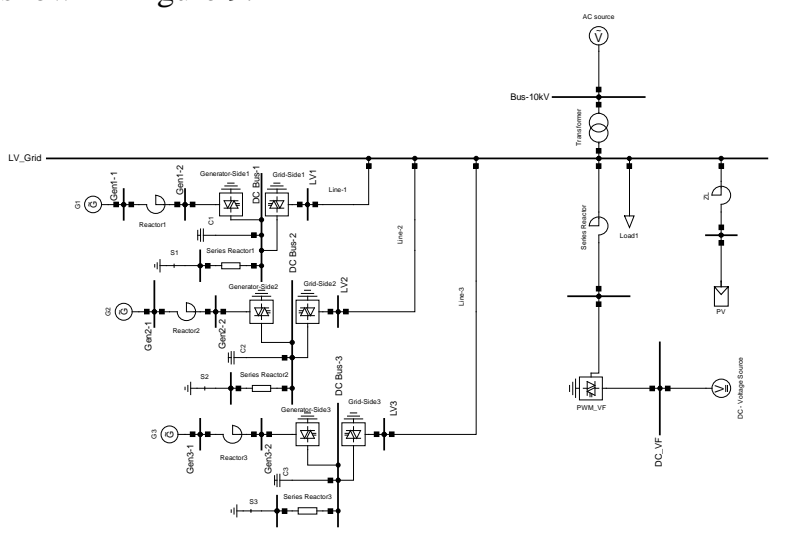

Fig. 9. Microgrid model structure diagram.

The simulation analysis content is to analyze the voltage and frequency characteristics of distribution network and distributed microgrid system in the process of microgrid switching.

Case1: In the grid-connected state, the active power of the WTs is $40 \mathrm{~kW}$, the active power of the PV inverter is $30 \mathrm{~kW}$, and the microgrid is switched off to the grid at $1.2 \mathrm{~s}$.

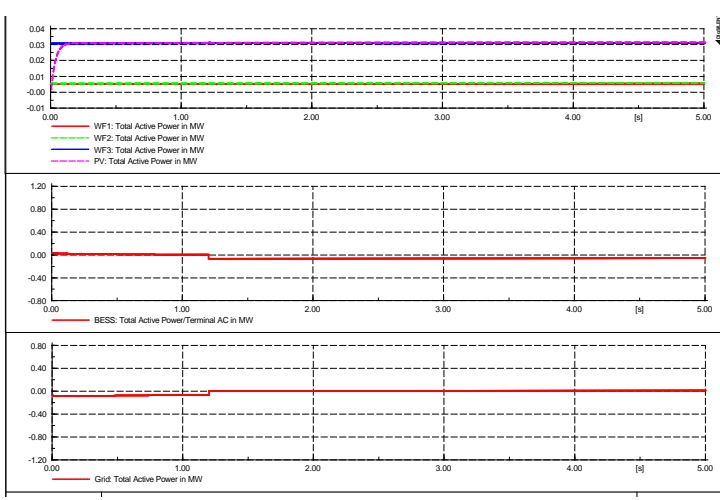

Fig. 10. Active power waveform diagram of PV,WT and PCS in case1.

As shown in Figure 10, the total active power and the PCS (BESS) active power fluctuate when the switch offs at $1.2 \mathrm{~s}$. The microgrid is under the island mode after 1.2s.At the time, the PCS supplies the power to the PV and WFs.

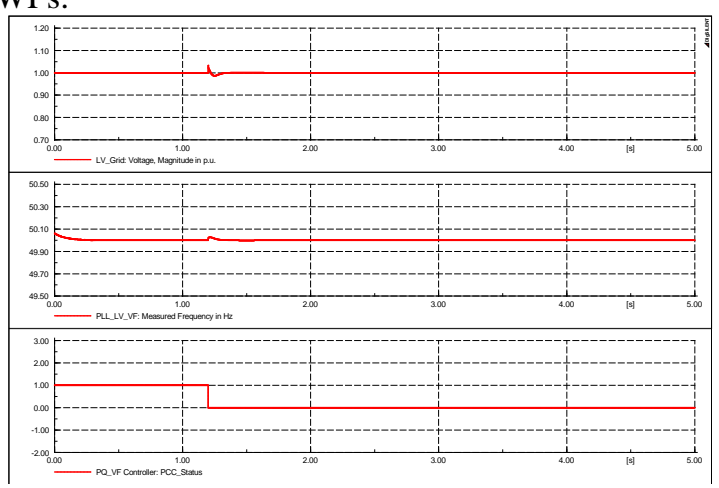

Fig. 11. Voltage and frequency waveform diagram of microgrid in case1.

It is shown that the output voltage and frequency of microgrid are stable when the microgrid is switching in Figure 11.

Case2: In the off-grid state, the load is supplied by the PV, WTs and PCS. The frequency of PCS is set to $50.1 \mathrm{~Hz}$, the active power of the WTs is set to $40 \mathrm{~kW}$, the active power of the PV inverter is set to $30 \mathrm{~kW}$, the load is set to $70 \mathrm{~kW}$, and the microgrid is connected to the grid at $1.2 \mathrm{~s}$.

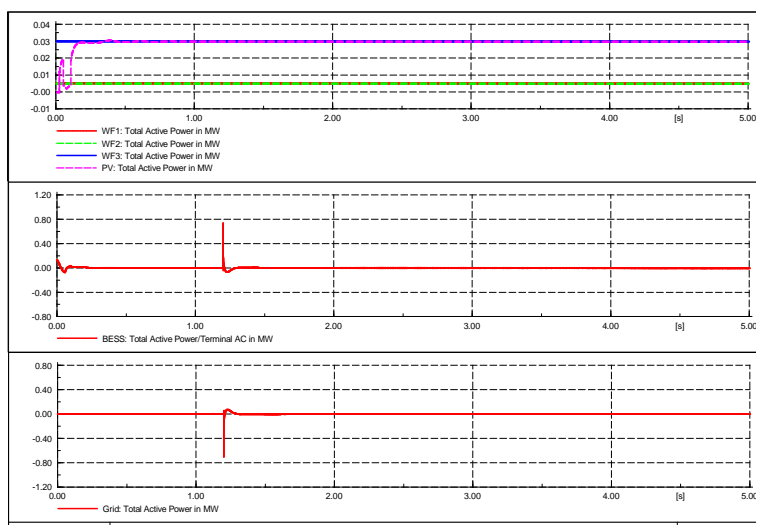


Fig. 12. Active power waveform diagram of PV,WT and PCS in case2.

As shown in Figure 12, the total active power and the PCS (BESS) active power fluctuate when the switch on at 1.2s. The microgrid is under the grid-connected mode after 1.2s.At the time, the active power of the PV and WFs supplies to the grid, and the load is connected to the grid too.

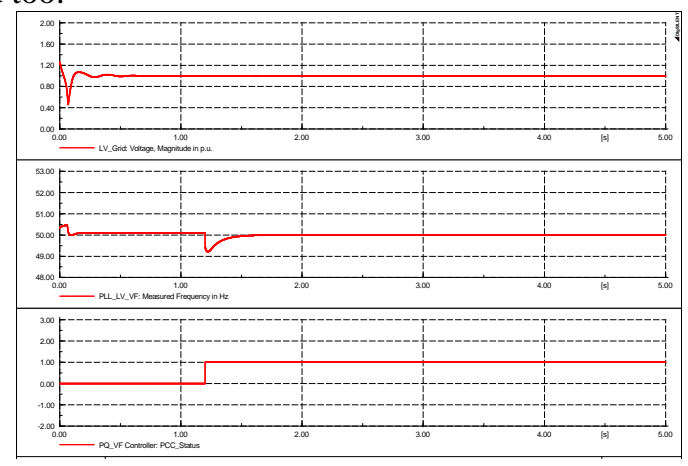

Fig. 13. Voltage and frequency waveform diagram of microgrid in case2.

It can be seen that when the microgrid is switched from the grid to the grid, the frequency of the microgrid fluctuates, but the voltage and frequency can be stably output and can be connected to the grid steadily, which is shown in figure 13.

\section{Comparison and verification of measurement and simulation}

In order to verify the accuracy of the overall model of the microgrid, microgrid switching tests were carried out in the microgrid system. The test contents are shown in Table 1.

Table 1. Test content.

\begin{tabular}{|c|c|c|}
\hline & Test condition & Test point \\
\hline On to Off & $\begin{array}{l}\text { In the grid-connected state, PV } 20 \mathrm{~kW} \text {, } \\
\text { PCS } 50 \mathrm{~kW} \text {, set be off the grid. }\end{array}$ & \multirow{2}{*}{$\begin{array}{l}\text { Distributed } \\
\text { power } \\
\text { supply } \\
\text { side 、 point } \\
\text { of common } \\
\text { coupling } \\
\text { (PCC) }\end{array}$} \\
\hline Off to On & $\begin{array}{l}\text { Case2: In the off-grid state, frequency } \\
\text { of PCS is } 50.1 \mathrm{~Hz}, \mathrm{PV} 20 \mathrm{~kW} \text {, set be } \\
\text { connected to the grid. }\end{array}$ & \\
\hline
\end{tabular}

Case1: In the grid-connected state, PV 20kW, PCS $50 \mathrm{~kW}$, set be off the grid. The test and simulation data contrast diagram is shown in figure 14-15.
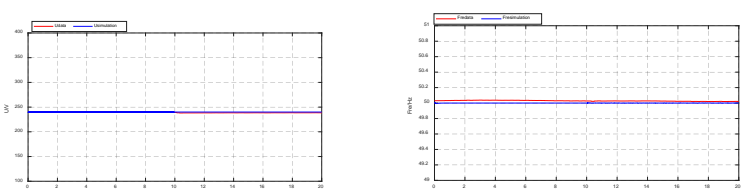

Fig. 14. PCC voltage and frequency contrast diagram in case1.

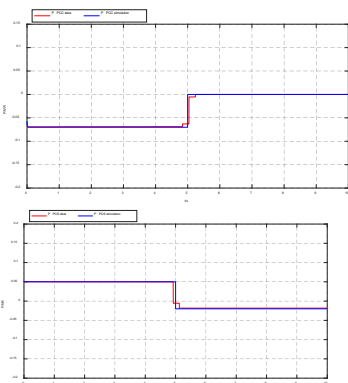

Fig. 15. PCC active power and PCS active power contrast diagram in case1.

In the steady-state interval before and after the switching, and the error calculation in the transient interval of the switching process, three kinds of error values are defined, which are the average deviation F1 of the steady state interval, the average deviation F2 of the transient interval, the maximum deviation F3 of the steady state interval, and the calculation results, as shown in Table 2.

Table 2. Test contentTest error analysis in case 1.

\begin{tabular}{|c|c|c|c|}
\hline & F1 & F2 & F3 \\
\hline PCC Voltage & 0.0045 & 0.024 & 0.015 \\
\hline PCC Frequency & 0.0002 & 0.0006 & 0.0005 \\
\hline PCC Active power & 0.014 & 0.029 & 0.062 \\
\hline PCS Active power & 0.0024 & 0.016 & 0.035 \\
\hline
\end{tabular}

Case2: In the off-grid state, frequency of PCS is $50.1 \mathrm{~Hz}$, PV $20 \mathrm{~kW}$, set be connected to the grid. The test and simulation data contrast diagram is shown in figure 16-17.
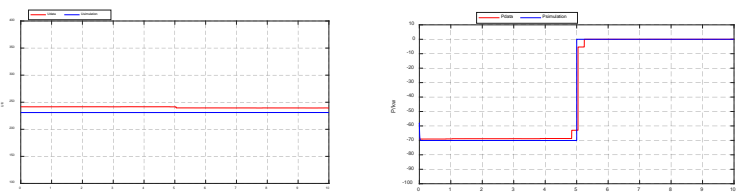

Fig. 16. PCC voltage and frequency contrast diagram in case2.

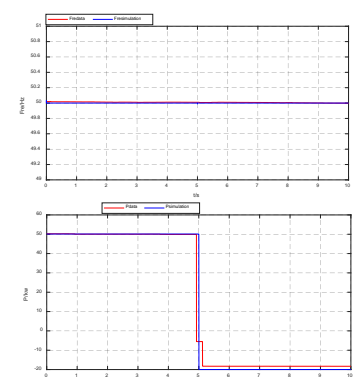

Fig. 17. PCC active power and PCS active power contrast diagram in case2.

It can be seen that the microgrid can run steadily in case 2, and the error between the measured data and the simulation data is small.

Table 3. Test content Test error analysis in case 2. 


\begin{tabular}{|c|c|c|c|}
\hline PCC Voltage & 0.016 & 0.037 & 0.033 \\
\hline PCC Frequency & 0.0003 & 0.0006 & 0.0005 \\
\hline PCC Active power & 0.0056 & 0.029 & 0.065 \\
\hline PCS Active power & 0.0018 & 0.14 & 0.16 \\
\hline
\end{tabular}

Through calculation, three kinds of error values which include F1, F2 and F3 are small either, as shown in Table 3. The microgrid model can accurately reflect its running characteristics.

\section{Conclusion}

This paper takes the $400 \mathrm{~V}$ AC microgrid system as the object, carries out the simulation and analysis of the measured modeling and Simulation of the $400 \mathrm{~V}$ microgrid with PV, WT and PCS. Based on the power system simulation software, the key equipment modeling is carried out, and the PV inverter, the WT and the PCS model are combined, and the functions can be realized according to the microgrid. In view of the microgrid's overall parameter testing, a microgrid model is established. Based on the above models, the simulation analysis is carried out for different working conditions, and compared with the measured waveforms for checking and verifying. On the basis of the experimental environment of the Academy of electricity, the field measurement of the microgrid switching is carried out, and the simulation waveform is checked and verified with the measured data. The results prove that the model is accurate and effective.

\section{Acknowledgment}

This study is supported by Science and technology project of State Grid Corporation of CHINA "Research on standard framework and certification standard of new energy generation under the background of internationalization" (Grant No. 52110417000F).

\section{References}

1. Sundar Venkataraman; Chris Ziesler; Peter Johnson; Stephanie Van Kempen.Integrated Wind, Solar, and
Energy Storage: Designing Plants with a Better Generation Profile and Lower Overall Cost. IEEE Power and Energy Magazine, 16 (2018)

2. Jingyang Fang, Xiaoqiang Li, Yi Tang. Energy storage system control strategy to minimize the voltage and frequency fluctuation in the microgird. 2018 IEEE Applied Power Electronics Conference and Exposition (APEC)

3. Huang jingsheng, Liu Meiying, Dongwei, Chen zhilei. Analysis and field-test on Reactive Capability of Photovoltaic plant based on clusters of inverters. Journal of Modern Power Systems and Clean Energy, 5 (2017)

4. YANG Zhangang, WANG Chengshan, CHE Yanbo. A small-scale microgrid system with fexible modes of operation. Automation of Electric Power Systems, 33 (2009)

5. ZHOU Lin, HUANG Yong, GUO Ke, et al. A survey of energy storage technology for micro grid. Power System Protection and Control, 39 (2011)

6. LIU Meiyin, HUANG Jingsheng, ZHANG Junjun, CAO lei. Photovoltaic Grid-connected Inverter Model Validation and Error Analysis based on the Standard of BDEW. Automation of Electric Power Systems, 38 (2014)

7. Umer Akram; Muhammad Khalid;Saifullah Shafiq. Optimal sizing of a wind/solar/battery hybrid gridconnected microgrid system. IET Renewable Power Generation, 2 (2018)

8. Emilien Duverger; Carolina Penin; Philippe Alexandre, et al. PV modeling methods of an offgrid experimental microgrid. IEEE International Conference on Industrial Technology, 2018.

9. J. A. P. Lopes; C. L. Moreira; A. G. Madureira. Defining control strategies for microgrids islanded operation. IEEE Trans on Power Systems, 21 (2006)

10. TIAN Liangyu, TANG Zhong, TIAN Chen, ZHU Ruiting.Research of Microgrid Seamless Switching Based on State Follower. Power System Technology, 41 (2017) 